The results described show an elaborate pattern of myofiber organization within $S$. mansoni cercariae. Some of the muscles, such as the pseudostriated fibers of the tail stem, are specific to this life cycle stage; some are identical (esophagus musculature) or similar (body wall musculature) to those found in the adult worm; others have yet to develop, e.g., those of the ducts of the male and female reproductive systems. Questions raised by this investigation include the process of myogenesis during transformation of the cercaria to schistosomule and adult worm and the functional properties of the different muscle systems in cercarial motility. Analyses of the swimming motions of $S$. mansoni cercariae reveal that the numerous longitudinal muscles of the tail stem contract alternately, bending it from side to side as a rowing device, with the furcae functioning as oar blades (Graefe et al., 1967). Comparison of larval and adult schistosome muscle patterns indicates new or additional growth of muscle fibers within the entire body, such as the diagonal fibers within the body wall musculature and muscle fibers underlying the paired intestinal ceca, and generation of the muscle components of the reproductive tracts. Some of the adult musculature may develop directly from larval musculature or grow from undifferentiated stem cells present in the larvae; however, there are no reports thus far that identify the mechanism of myogenesis in the transformation of cercaria to the adult schistosome.

Clearly, as the tissues responsible for motility, body wall musculature and tail musculature play an important role in host location for the shortlived cercaria. Innervation of muscle in Schistosoma has been shown to be reactive to both classical (acetylcholine and biogenic amines) and peptide neurotransmitters/modulators (FMRFamide-related peptides and the neuropeptide Y homologue neuropeptide F) (see Halton and Gustafsson, 1996, for a review). An involvement of neuroactive substances in muscle control in Schistosoma has been demonstrated in experiments using individual muscle fibers isolated from the worm (Day et al., 1994, 1997).

This work was funded by NIH grant ROI-AI49162. We are grateful to Fred A. Lewis, Schistosomiasis Laboratory, Biomedical Research Institute, Rockville, Maryland, for supplying the infected B. glabrata snails used in this work through NIH-NIAID contract NO1-AI-55270 and to Gerard P. Brennan, Queen's University Belfast, for assistance with the scanning electron microscopy.

\section{LITERATURE CITED}

Cohen, L. M., H. Neimark, And L. K. Eveland. 1980. Schistosoma mansoni: Response of cercariae to a thermal gradient. Journal of Parasitology 66: 362-364.

Combes, C., A. Fournier, H. Mone, And A. Theron. 1994. Behaviours in trematode cercariae that enhance parasite transmission: Patterns and processes. Parasitology 109: S3-S13.

Cousin, C., C. Dorsey, V. Kennedy, And K. Ofori. 1995. Ultrastructure of the ventral sucker of Schistosoma mansoni cercaria. Journal of Morphology 223: 215-223.

Day, T. A., A. G. Maule, C. Shaw, D. W. Halton, S. Moore, J. L. BennetT, AND R. A. PAX. 1994. Platyhelminth FMRFamide-related peptides (FaRPs) contract Schistosoma mansoni (Trematoda; Digenea) muscle fibres in vitro. Parasitology 109: 445-459.

$\longrightarrow,-,-$ AND R. A. PAX. 1997. Structure-activity relationships of FMRFamide-related peptides induced contractions of Schistosoma mansoni muscle. Peptides 18: 917-921.

Dorsey, C. H., C. E. Cousin, F. A. Lewis, and M. A. Stirewalt. 2002. Ultrastructure of the Schistosoma mansoni cercaria. Micron 33: 279-323.

Fetterer, R. H., R. A. Pax, S. Strand, and J. L. Bennett. 1978. Schistosoma mansoni: Physical and chemical factors affecting the mechanical properties of the adult male musculature. Experimental Parasitology 46: 59-71.

Graefe, G., W. Hohorst, and H. Drager. 1967. Forked tail of the cercaria of Schistosoma mansoni-A rowing device. Nature 215: 207-208.

HaAs, W., D. Diekhoff, K. Koch, G. Schmalfuss, and C. Loy. 1997. Schistosoma mansoni cercariae: Stimulation of acetabular gland secretion is adapted to the chemical composition of mammalian skin. Journal of Parasitology 83: 1079-1085.

Halton, D. W., and M. K. S. Gustafsson. 1996. Functional morphology of the platyhelminth nervous system. Parasitology 113: S47S72.

Hochberg, R., AND M. Litvaitis. 2001. The muscular system of Dactylopodola baltica and other macrodasyidan gastrotrichs in a functional and phylogenetic perspective. Zoologica Scripta 30: 325336.

Hooge, M. D., AND S. Tyler. 1999. Musculature of the facultative parasite Urastoma cyprinae (Platyhelminthes). Journal of Morphology 241: 207-216.

LuMSDEN, R. D., AND W. E. FoOR. 1968. Electron microscopy of schistosome cercarial muscle. Journal of Parasitology 54: 780-794.

Mair, G. R., A. G. Maule, T. A. Day, and D. W. Halton. 2000. A confocal microscopical study of the musculature of adult Schistosoma mansoni. Parasitology 121: 163-170.

NuttMan, C. J. 1974. The fine structure and organization of the tail musculature of the cercaria of Schistosoma mansoni. Parasitology 68: $147-154$.

REGER, J. F. 1976. Studies on the fine structure of cercarial tail muscle of Schistosoma sp. (Trematoda). Journal of Ultrastructure Research 57: 77-86.

Reiter, D., B. Boyer, P. Ladurner, G. R. Mair, W. Salvenmoser, And R. M. RIEGER. 1996. Differentiation of the body wall musculature in Macrostomum hystricinum marinum and Hoploplana inquilina (Plathelminthes), as models for muscle development in lower Spiralia. Rouxs Archives of Developmental Biology 205: 410-423.

TYleR, S., AND R. M. RIEGER. 1999. Functional morphology of the acoelomate worm, Convoluta pulchra (Platyhelminthes). Zoomorphology 119: 127-141.

Ward, S. M., G. McKerr, And J. M. Allen. 1986. Structure and ultrastructure of muscle systems within Grillotia erinaceus metacestodes (Cestoda: Trypanorhyncha). Parasitology 93: 587-597.

\title{
From First to Second and Back to First Intermediate Host: The Unusual Transmission Route of Curtuteria australis (Digenea: Echinostomatidae)
}

\author{
L. H. McFarland, K. N. Mouritsen, and Robert Poulin*, Department of Zoology, University of Otago, P.O. Box 56, Dunedin, New Zealand. ${ }^{\star}$ To \\ whom correspondence should be addressed. e-mail: robert.poulin@stonebow.otago.ac.nz
}

ABSTRACT: The trematode Curtuteria australis uses the whelk Cominella glandiformis as first intermediate host and the cockle Austrovenus stutchburyi as second intermediate host before maturing in shorebirds. The whelk also happens to be an important predator of cockles on intertidal mudflats. In this study we show that whelks can act as tem- porary paratenic hosts for the trematode. A single whelk feeding on 1 cockle can ingest large numbers of metacercariae, which remain within the whelk for 1-3 days before passing out in feces. The viability of these metacercariae, assessed as the percentage capable of successfully excysting under conditions simulating those inside a bird's digestive 
tract, is lower after passage through a whelk (48\%) than before $(59 \%)$. Still, given that shorebird definitive hosts prey on whelks as well as cockles, survival inside the whelk allows $C$. australis to complete its life cycle; overall, though, whelk predation is likely to be an important sink for the trematode population. To our knowledge, this is the first report of a trematode using a snail as both first intermediate host and paratenic host, offering an alternative transmission route for the parasite as a result of the unusual trophic relationships of its hosts.

The life cycle of a typical trematode involves 3 hosts: a definitive host in which the adult worms live, a first intermediate host in which the parasite multiplies asexually to produce cercariae, and a second intermediate host in which cercariae encyst as metacercariae and awai ingestion by the definitive host. In trematode species using this basic life cycle, however, the parasites may also take alternative transmission routes. For instance, in many species, the life cycle can be abbreviated, with the parasite facultatively omitting 1 or more hosts (Poulin and Cribb, 2002). In addition, trematode life cycles may have additiona paratenic hosts, although this possibility often goes unnoticed; paratenic hosts are hosts that may play roles in transmission but in which no parasite development takes place. Intermediate hosts of trematodes may be parts of complex networks of trophic relationships, and for some species many roads may lead to the definitive host. For example, the microphallid Maritrema arenaria uses barnacles as second intermediate hosts and birds as definitive hosts. McCarthy et al. (1999) recently documented that metacercariae of $M$. arenaria survive passage through the predatory snail Nucella lapillus, which feeds on barnacles. Because the bird definitive hosts of the parasite feed on the snails as well as barnacles, the trematode can use $N$. lapillus as paratenic hosts. Alternative transmission pathways like this one may be common in natural systems, where trematodes may accommodate the various trophic relationships involving their hosts.

The trematode Curtuteria australis (Echinostomatidae) may be in such a situation. Adult $C$. australis live in the gut of oystercatchers Haematopus spp. (Allison, 1979) but also occur in gulls Larus spp. (B. L. Fredensborg, pers. comm.) and probably other shorebirds. They use the whelk Cominella glandiformis (Buccinidae) as first intermediate hosts and the common cockle Austrovenus stutchburyi (Veneridae) as second intermediate hosts, in which they encyst in the foot (Allison, 1979). Whelks are common scavengers-predators on soft-sediment intertidal areas throughout New Zealand (Morton and Miller, 1973). They are often seen feeding in groups on a cockle, leaving behind only a clean shell. Ansell (2001) estimated that 3-9\% of cockles fall prey to whelks every year. Predation of a second intermediate host by the first intermediate host is unusual among known trematode life cycles. In the Otago Harbour (South Island, New Zealand), the prevalence of C. australis metacercariae in cockles is virtually $100 \%$, and mean numbers of metacercariae per cockle exceed 100 in most localities. Thus, whelks accidentally ingest large numbers of metacercariae, representing a considerable proportion, i.e., 3-9\%, of the pool of available metacercariae Oystercatchers and other potential avian definitive hosts of $C$. australis are known to feed on whelks (Fordham, 1970; Baker, 1974). If metacercariae remain viable during their passage inside whelks, they could use these snails as paratenic hosts. This would allow the trematode to extend its chance of transmission to birds beyond the death of the cockle host. The aim of the present study was to assess the potential role of whelks as paratenic hosts for $C$. australis using feeding experiments under laboratory conditions.

Whelks and cockles were collected in June 2002 from Lower Portobello Bay, Otago Harbour, close to the low watermark, and returned live to the laboratory. Cockles were kept in a large tank filled with seawater, at room temperature (20-25 C) and under a natural photoperiod. Whelks were kept under the same conditions but placed individually in small plastic containers (4-cm diameter) half-filled with seawater.

For the feeding experiment, 40 whelks (shell height $17.0 \pm 0.2 \mathrm{~mm}$ [mean $\pm \mathrm{SE}]$ ) were starved for 3 days before each was fed the foot of 1 cockle. In each case, the cockle foot was measured (length at the base) and cut off and then pressed firmly between 2 microscope slides. Metacercariae visible on each side of the foot were counted under the microscope $(\times 10)$ before the entire intact foot was given to a whelk to feed on. These visual estimates of the number of metacercariae per cockle foot slightly but consistently underestimate the true number. In a separate sample of 15 cockles, we obtained both a visual estimate of the number of metacercariae in the foot and an actual total count obtained after digestion of the foot in a pepsin solution $(6 \mathrm{~g}$ pepsin and 7 $\mathrm{ml} \mathrm{HCl}$ in $1,000 \mathrm{ml}$ water) at $40 \mathrm{C}$ for $4 \mathrm{hr}$. This procedure allows the recovery and count of all metacercariae under the microscope, including those that were not visible because they were deeply embedded in the foot (Lepitzki et al., 1994). From these 15 cockles, we obtained a regression equation (actual number $=64.6+1.57$ (visual estimate), $r^{2}=$ $0.87, P=0.0001$ ) that allowed actual numbers of metacercariae per foot to be extrapolated for all cockle feet fed to whelks.

After $1.5 \mathrm{hr}$ of feeding on a cockle foot (most whelks had finished feeding within $1 \mathrm{hr}$ ), each whelk was transferred to a new container with fresh seawater. Cockle flesh, if any, remaining in the original containers was digested in a pepsin solution, as above, and the remaining metacercariae were counted and subtracted from the total number initially given to the whelks to obtain the number actually eaten. Four of the 40 whelks were excluded from the experiment because they either did not eat any foot tissue or did not produce feces, leaving 36 whelks in the following analyses. During the 5 days after the feeding period, fecal checks were made 4 times daily. When feces were found, they were pipetted out of the whelk's container, placed in a petri dish, and examined under the microscope. The number of metacercariae in each fecal deposit was recorded. Their viability was assessed by in vitro excystment under conditions simulating those inside a bird's digestive tract. The metacercariae were placed in petri dishes in an excystment solution consisting of $5 \mathrm{ml}$ of bicarbonate saline $(0.8 \% \mathrm{w} / \mathrm{v}$ sodium chloride and $1.5 \% \mathrm{w} / \mathrm{v}$ sodium bicarbonate) containing $0.8 \% \mathrm{w} / \mathrm{v}$ sodium taurocholate and $0.3 \% \mathrm{w} / \mathrm{v}$ trypsin, and $5 \mathrm{ml} 0.02 \mathrm{M}$ hydrochloric acid containing 0.8\% w/v L-cysteine (Irwin et al., 1984; Irwin, 1997). They were left in the solution for $1 \mathrm{hr}$ at $40 \mathrm{C}$ and then examined under the microscope $(\times 40)$. Fully excysted and moving worms were counted as viable, whereas those not fully excysted or motionless were considered as dead.

To compare these results with the viability of metacercariae that have not passed through a whelk, the foot of each of 20 cockles was measured and cut off. The number of metacercariae it contained was estimated as above. These 20 cockles did not differ in either foot length $(t$ $=0.453, P=0.652$ ) or numbers of metacercariae harbored (using logtransformed data: $t=0.257, P=0.798$ ) from those fed to whelks. The foot was then carefully fragmented in seawater using needles and placed in a weak pepsin solution ( $1 \%$ pepsin, $0.85 \% \mathrm{NaCl}, \mathrm{pH} 2)$ to remove layers of host tissue and expose the metacercariae (Irwin, 1997). These were then placed in the excystment solution and assessed for viability as those recovered from whelk feces.

A total of 4,373 (range 6-281 per snail) metacercariae of C. australis were recovered from the feces of the 36 experimental whelks. None had passed out $24 \mathrm{hr}$ after their ingestion by whelks; after $48 \mathrm{hr}$, approximately $50 \%$ of the metacercariae had come out, and by $72 \mathrm{hr}$ after ingestion, they had all been evacuated. There was a relatively strong positive correlation between the number of metacercariae eaten by a whelk and the number recovered from its feces $(r=0.689, P=0.0001)$ : the more metacercariae went in, the more came out (Fig. 1). The lack of an obvious asymptote (even with untransformed data) suggests that within the range of numbers ingested by the whelks, there is no clear upper limit on how many metacercariae can transit through a whelk.

The viability of metacercariae, i.e., the percentage that excysted, showed no density dependence. Rather, the percentage of viable metacercariae among those egested by whelks correlated positively with the number of metacercariae eaten $(r=0.413, \mathrm{n}=36, P=0.0124)$. This association likely results from the percentage of viable metacercariae being correlated positively with the total number of metacercariae in the cockles from which they originated $(r=0.401, \mathrm{n}=36, P=$ $0.0154)$. The more heavily infected cockles had perhaps been exposed to recent waves of infection, resulting in a high proportion of new viable metacercariae in their tissue. Whatever the explanation, it is clear that the viability of metacercariae in whelks is not decreased when high numbers are ingested. The viability is also not seriously affected by passage time through the whelks. A comparison of metacercariae in feces egested within $48 \mathrm{hr}$ after ingestion with those egested more than $64 \mathrm{hr}$ after ingestion indicates no significant difference in viability ( $t=$ $1.66, P=0.106)$, although lower percentages of excystment were more common in groups of metacercariae from the latter group. There was, however, an effect of ingestion by and passage through a whelk on 


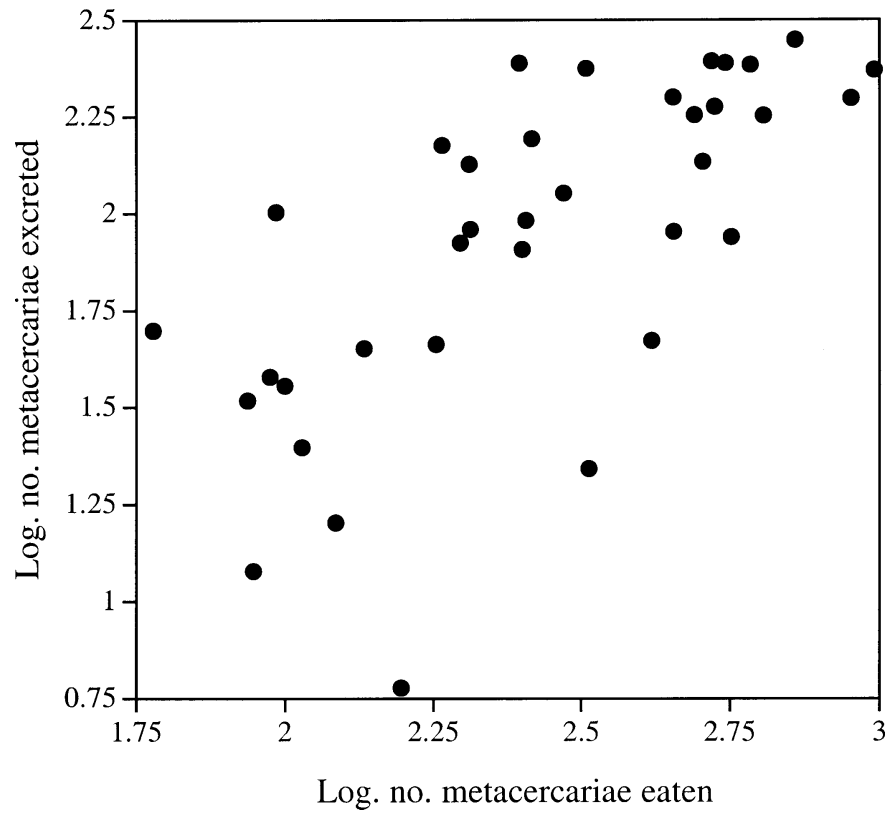

FIGURE 1. Relationship between the number of metacercariae of the trematode Curtuteria australis ingested by whelks and the number that passed out in whelk feces.

metacercarial viability (Fig. 2). The viability of metacercariae that passed through whelks was on average 19\% lower than that of metacercariae taken straight out of cockles (using arcsine-transformed data: $t=2.159, P=0.0353$ ).

Our results show that metacercariae of the trematode $C$. australis can survive passage through a whelk when the latter preys on cockles. Metacercariae can stay up to 3 days in whelks, and about half of them are viable and can develop into adults should a bird definitive host feed on the whelk. To our knowledge, this is the first report of a snail first intermediate host also being used as a paratenic host by a trematode, thus accommodating the unusual trophic relationship between its hosts.

Almost $60 \%$ of metacercariae taken straight from cockles and placed in the cysteine solution excysted successfully. Clearly, dead metacercariae remain in cockle tissues for some time. The significantly lower excystment rate observed in metacercariae that passed through a whelk suggests that there is an additional mortality factor associated with this passage. The most likely cause is the possible physical damage that some metacercariae may incur as whelks feed on cockle tissue. Although the metacercariae are small (200-250 $\mu \mathrm{m}$ in diameter), their cyst risks being punctured by the whelk's radula during feeding. Still, the survivorship of the trematode in its temporary paratenic whelk host is high enough to provide an extended transmission period after the death of the second intermediate host.

The trematode may indirectly facilitate predation of whelks on cockles and thus inadvertently increase its likelihood of passing through a whelk. Metacercariae of C. australis are found encysted in the foot of cockles, directly impairing the burrowing ability of their cockle host and leaving them stranded at the surface of the sediments (Thomas and Poulin, 1998; Mouritsen, 2002). This results in increased bird predation on cockles and therefore increased parasite transmission to the definitive host (Thomas and Poulin, 1998), but it should also make it easier for whelks to find and prey on cockles. If these also happen to be the most heavily infected, much more than 3-9\% (based on Ansell, 2001) of $C$. australis metacercariae may pass through whelks. This alternative transmission route may therefore be taken by a large proportion of metacercariae. However, given their short residence time in whelks, many of them will be lost from the system; although a few metacercariae reach birds after ingestion by a whelk, in general, whelk predation represents an important sink for the trematode population.

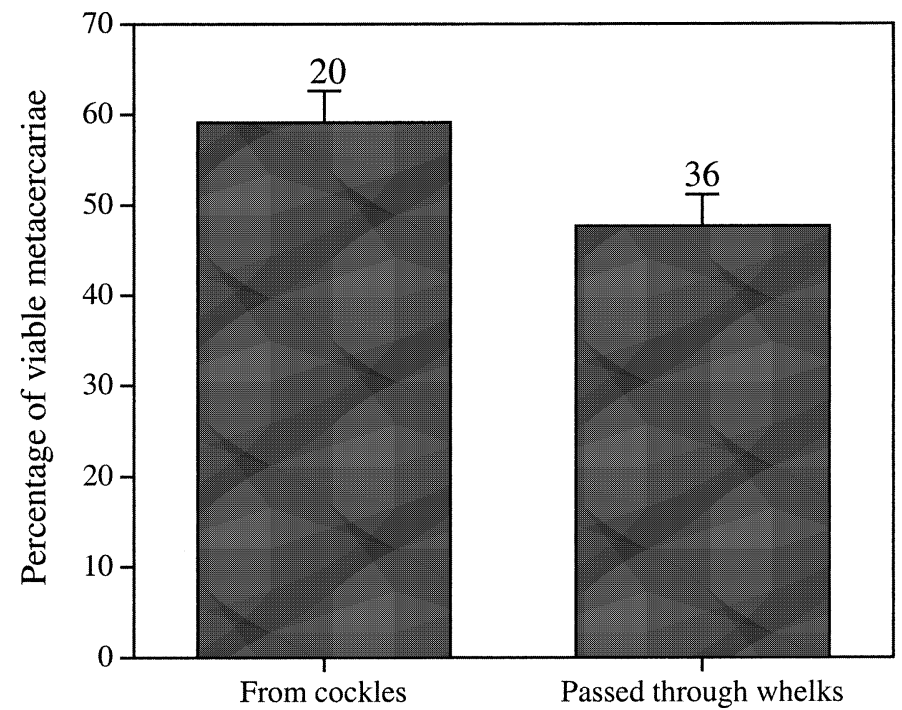

Origin of metacercariae

FIGURE 2. Mean \pm SE viability (percentage of worms that excysted successfully) of metacercariae of the trematode Curtuteria australis taken directly from its cockle second intermediate host or after passage through whelks. Numbers of cockles or whelks from which the metacercariae were obtained are indicated above each column.

Whelks are unlikely to serve as temporary paratenic hosts for another trematode parasitic in cockles, which matures in avian hosts just as $C$. australis. An unidentified gymnophallid occurs in cockles in the Otago area, although at a lower prevalence and in fewer localities than $C$. australis; its metacercariae are found in host epithelium near the hinge of the shell (Poulin et al., 2000). They could not survive inside a whelk after predation on cockle hosts, however, because they are not encysted. Still, the results presented in this study demonstrate that parasite transmission can follow routes other than the classical life cycles presented in textbooks and that transmission must be considered within the framework of the trophic interactions in which it operates in nature.

We thank J. Duthie and K. Hedley for technical assistance and S. W. B. Irwin for advice. This research was partially supported by a grant from the Marsden Fund, and K.N.M. was supported by the Danish Natural Science Research Council.

\section{LITERATURE CITED}

Allison, F. R. 1979. Life cycle of Curtuteria australis n. sp. (Digenea: Echinostomatidae: Himasthlinae), intestinal parasite of the South Island pied oystercatcher. New Zealand Journal of Zoology 6: 1320.

ANSELL, A. D. 2001. Dynamics of aggregations of a gastropod predator/ scavenger on a New Zealand harbour beach. Journal of Molluscan Studies 67: 329-341.

BAKER, A. J. 1974. Prey specific feeding methods of New Zealand oystercatchers. Notornis 21: 219-233.

FoRDHAM, R. A. 1970. Mortality and population change of dominican gulls in Wellington, New Zealand. Journal of Animal Ecology 39: $13-27$.

IRwIN, S. W. B. 1997. Excystation and cultivation of trematodes. In Advances in trematode biology, B. Fried and T. K. Graczyk (eds.). CRC Press, Boca Raton, Florida, p. 57-86.

-, G. McKerr, B. C. Judge, And I. Moran. 1984. Studies on metacercarial excystment in Himasthla leptosoma (Trematoda: Echinostomatidae) and newly emerged metacercariae. International Journal for Parasitology 14: 415-421.

Lepitzki, D. A. W., M. E. ScotT, And J. D. McLaughlin. 1994. Influence of storage and examination methods on the recovery and size of metacercariae of Cyathocotyle bushiensis and Sphaeridotrema pseudoglobulus (Digenea). Journal of Parasitology 80: 454-460.

McCarthy, H. O., S. W. B. Irwin, and S. M. FitZPatRick. 1999. Nu- 
cella lapillus as a paratenic host for Maritrema arenaria. Journal of Helminthology 73: 281-282.

Morton, J., AND M. Miller. 1973. The New Zealand sea shore, 2nd ed. Collins, London, U.K., 653 p.

Mouritsen, K. N. 2002. The parasite-induced surfacing behaviour in the cockle Austrovenus stutchburyi: A test of an alternative hypothesis and identification of potential mechanisms. Parasitology 124: $521-528$.
Poulin, R., And T. H. CRibi. 2002. Trematode life cycles: Short is sweet? Trends in Parasitology 18: 176-183.

-, M. J. Steeper, AND A. A. Miller. 2000. Non-random patterns of host use by different parasite species exploiting a cockle population. Parasitology 121: 289-295.

Thomas, F., AND R. Poulin. 1998. Manipulation of a mollusc by a trophically transmitted parasite: Convergent evolution or phylogenetic inheritance? Parasitology 116: 431-436.

J. Parasitol., 89(3), 2003, pp. 628-630

(C) American Society of Parasitologists 2003

\title{
Protracted Shedding of Oocysts of Neospora caninum by a Naturally Infected Foxhound
}

\author{
J. W. McGarry, C. M. Stockton, D. J. L. Williams, and A. J. Trees, Veterinary Parasitology Group, Liverpool School of Tropical Medicine and
} Faculty of Veterinary Science, University of Liverpool, Pembroke Place, Liverpool L3 5QA, U.K. e-mail: j.w.mcgarry@liverpool.ac.uk

ABSTRACT: Feces from 15 dogs at 2 different foxhound kennels in the U.K. were examined microscopically for the presence of oocysts of Neospora caninum. One sample containing approximately 400 candidate oocysts per gram was positive in a polymerase chain reaction (PCR) using $N$. caninum-specific primers. In a sample taken 4 mo later from the same hound, $N$. caninum oocysts were again detected visually and by PCR. This is the third reported case of a dog naturally excreting oocysts of $N$. caninum and suggests that oocyst excretion can occur over a relatively long period of time in some circumstances or that reshedding may occur.

Neospora caninum is the most frequently diagnosed cause of abortion in cattle throughout the world (Dubey, 1999). The major route of transmission in cattle is transplacental (Dubey and Lindsay, 1996), but there is circumstantial evidence that epidemic $N$. caninum-associated abortions in cattle are caused by external sources of infection (Yaeger et al., 1994; McAllister et al., 1996; Dijkstra, Barkema et al., 2001). Dogs have been shown to be definitive hosts of $N$. caninum, shedding oocysts after experimental infection (McAllister et al., 1998; Lindsay et al., 1999). Point sources of infection are likely to be caused by oocyst contamination of pasture or feed. Infections in cattle herds have been linked to infections in dogs (Wouda et al., 1999). An association between abortion risk or the occurrence of postnatal infection and abortion and the presence of dogs has been found (Parè et al., 1998; Bartels et al., 1999; Djikstra et al., 2002). Calves and cows have been infected experimentally by oocysts (De Marez et al., 1999; Trees et al., 2002), but low doses of oocysts do not cause abortion in cows.

The number of oocysts and the dynamics of their excretion into the environment profoundly influence the epidemiology of coccidian diseases such as ovine toxoplasmosis. In the acute phase of infection, cats may shed several million oocysts of Toxoplasma gondii in 1-2 wk (Dubey and Frenkel, 1972; Dubey, 1976). In some flocks in the U.K., 70-90\% of sheep are seropositive for T. gondii (Watson and Beverley, 1971). Approximately 1,500 T. gondii oocysts or fewer provoke abortion in sheep (Owen et al., 1998), but the minimal pathogenic dose is unclear. Dogs fed tissue containing $N$. caninum cysts shed low numbers of oocysts inconsistently for up to 19 days (McAllister et al., 1998; Lindsay et al., 1999; Dijkstra, Eysker et al., 2001). The detection of oocysts of $N$. caninum has been reported from 2 naturally infected dogs. In 1 case, the number of oocysts excreted was undetermined but was thought to be low (Basso et al., 2001), and in the other a total of 1 million oocysts were recovered using a sugar concentration method (Šlapeta et al., 2002). The pattern of excretion or quantity of feces examined was not reported.

In the U.K., foxhounds are routinely fed bovine carcasses and have a higher prevalence of $N$. caninum antibodies than do pet dogs (Trees and Williams, 2000). We, therefore, investigated their role as definitive hosts. Polymerase chain reaction (PCR) was used to confirm the identity of oocysts because the investigation of definitive hosts for N.caninum has been complicated by the presence of oocysts of other apicomplexan parasites, e.g., Hammondia spp. (Schares et al., 2002). Here, we report the case of a 6-yr-old British foxhound that had shed low numbers of oocysts when examined on 2 occasions almost 4 mo apart. The epidemiological significance of these observations is discussed.

During the period April-June 1999, 15 fresh fecal samples were obtained from 2 different foxhound kennels in the north of U.K. All hounds were bred on site but were fostered in domestic homes before returning to the packs at approximately $18 \mathrm{mo}$ of age. Ages varied from 18 mo to 8 yr. Samples were taken from the pens of individual animals isolated the night before. One male dog in which putative $N$. caninum oocysts were detected was sampled on 3 occasions: 16 June 1999, 15 October 1999, and 4 November 1999.

Fecal samples were screened by microscopy after centrifugal flotation in saturated sodium chloride using a semiquantitative coverslip method. Briefly, $1 \mathrm{~g}$ of feces was homogenized by vortexing in $15 \mathrm{ml}$ of saturated $\mathrm{NaCl}$ with glass beads. A coverslip was placed immediately on top of the tube, and the tube was centrifuged at $700 \mathrm{~g}$ for $2 \mathrm{~min}$ and quickly lifted off. Protozoan cysts were counted. For PCR, $10 \mathrm{~g}$ of feces was homogenized in $50 \mathrm{ml}$ of distilled water and washed 3 times after straining through a $100-\mu \mathrm{m}$-mesh sieve. The final sediment was mixed with saturated $\mathrm{NaCl}$ and centrifuged as above. The surface layer of the supernatant that contained oocysts was washed 3 times in water and resuspended in $100 \mu \mathrm{l}$ of Tris-ethylenediaminetetraacetic acid buffer, $\mathrm{pH}$ 8.0. DNA was prepared from the suspension using a DNeasy ${ }^{\mathrm{R}}$ kit according to the manufacturer's instructions for DNA extraction from tissues (Qiagen, Crawley, Sussex, U.K.).

To confirm that the DNA extraction procedure was effective using oocysts, experimentally produced $N$. caninum oocysts (obtained from M. M. McAllister, Department of Veterinary Pathobiology, VMBSB, Urbana, Illinois) were diluted in water and processed using the Dneasy $\mathrm{R}^{\mathrm{R}}$ kit (Qiagen). Neospora caninum DNA could be detected in water suspensions nominally containing a single oocyst per milliliter by PCR using the primers of Uggla et al. (1998) and Ellis et al. (1999).

DNA extracted from hound fecal samples in which oocysts had been detected by microscopy was used in PCRs using different $N$. caninum primer sets (Muller et al., 1996; Uggla et al., 1998; Ellis et al., 1999) for $N$. caninum. Two sets of $H$. heydorni-specific primers, forward primer 5'-ACGGATTCGGCGATTGAAG-3' and reverse primer $5^{\prime}$ CATCGCGTCTTCTGATTC-3', and forward primer 5' -TGAATCCCAAGCAAAACA-3' and reverse primer 5' -CTGGCATCGCATAGAGAA-3'), designed from the ITS1 region of $H$. heydorni (Ellis, Morrison et al., 1999) were tested with the sample that was PCR positive for $N$. caninum. All PCR methods were modified for use with Hot Star TAQ polymerase with recommended buffer conditions (Qiagen). Controls included in each PCR were N. caninum (Liverpool, U.K.) tachyzoite DNA or $H$. heydorni DNA used alone or spiked into DNA extracted from oocyst-negative fecal samples.

Of the 10 fecal samples taken from kennel 1 ( 80 foxhounds in the pack), 1 sample contained 378 putative $N$. caninum oocyts per gram, estimated using the semiquantitative coverslip method described earlier. Three samples contained oocysts of Sarcocystis spp. Of the 5 fecal samples examined from kennel 2 (60 foxhounds in the pack), 1 sample 